\title{
Planejamento estratégico participativo e seus efeitos no clima organizacional
}

\section{Leiliane Penafort da Silva ${ }^{1}$, Ananias Costa Oliveira ${ }^{2}$, Luis de Jesus Pereira ${ }^{3}$ e Cláudio Marcio Campos de Mendonça ${ }^{4}$}

\author{
1 Universidade Federal do Amapá - UNIFAP. E-mail: leilianesilva-unifap@hotmail.com \\ 2 Universidade Federal do Amapá - UNIFAP. E-mail: ananiasoliveira@unifap.br \\ 3 Universidade Federal do Amapá - UNIFAP. E-mail: luis_jpereira@yahoo.com.br \\ 4 Universidade Federal do Amapá - UNIFAP. E-mail: cmarcio@gmail.com
}

RESUMO: O objetivo deste artigo é investigar a participação no planejamento estratégico como fator de satisfação e influência no clima organizacional. O universo amostral é a PróReitoria de Gestão de Pessoas - PROGEP, da Universidade Federal do Amapá - UNIFAP. Quanto à abordagem do problema, esta pesquisa se caracteriza como qualitativa e quantitativa, e do ponto de vista dos seus objetivos é classificada de tipo exploratória e descritiva. A coleta de dados foi realizada por meio de questionário com 22 servidores e entrevistas com 3 gestores, correspondendo a uma parcela de $69 \%$ de seu público-alvo. O resultado geral da pesquisa indicou um nível de $86 \%$ de satisfação dos servidores, evidenciando que envolver as pessoas nas decisões e na construção de instrumentos estratégicos da instituição contribuiu para fomentar a gestão participativa e melhorar o clima organizacional entre os envolvidos.

Palavras-chave: Gestão Participativa. Planejamento Estratégico. Clima Organizacional.

\section{Participatory strategic planning and its effects on organizational climate}

\begin{abstract}
The aim of this article is to explore the participation in strategic planning as a satisfaction factor and his influence in organizational climate. The sample frame is the Dean's Office Personnel (PROGEP) of the Federal University of Amapá - UNIFAP. As for the approach to the problem, this research makes use of both qualitative and quantitative methods, and from the point of view of its objectives is classified as exploratory and descriptive. The data collection was done using questionnaire sheets which were filled by 22 civil servants and interviews with 3 managers, which corresponds to a share of 69 percent of its target audience. The general research result reported a satisfaction level of 86 percent of the civil servants, and this shows us that the involvement of people in decision making as well as in building strategic instruments of the organization has helped to foster participatory management and improve the organizational climate among stakeholders.
\end{abstract}

Keywords: Participatory Management. Strategic Planning. Organizational Climate.

\section{INTRODUÇÃO}

No contexto atual de mudanças e de desenvolvimento tecnológico vivenciado pelas organizações, faz-se necessário uma gestão organizacional estruturada e bem planeja- da, com o propósito de conduzir pessoas e processos de forma eficaz, promover meIhorias, criar um ambiente colaborativo, motivado, propício ao autodesenvolvimento e, consequentemente, à conquista de resultados positivos. 
Neste sentido, conduzir a organização em um caminho onde seus objetivos sejam alcançados de forma eficiente, é uma tarefa desafiadora. Diante desse contexto, estudiosos se dedicam a criar modelos e teorias de gestão com ênfase a orientar as organizações no alcance de seus objetivos, de forma eficaz, por meio de gestores e demais colaboradores. O planejamento estratégico é uma das grandes ferramentas advinda desses estudos.

Vale ressaltar, que as organizações são compostas por recursos, competências e, principalmente por pessoas, sua maior vantagem competitiva. Neste contexto, tornase fundamental alinhar as estratégias organizacionais por meio da gestão participativa na construção de um instrumento de planejamento.

Chiavenato (2016) ratifica que, cada vez mais, torna-se necessária a participação das pessoas no processo decisório organizacional, uma vez que elas colocam em prática as ações definidas e alimentam os indicadores. Assim, o processo de elaboração das estratégias não deve ser construído somente por gestores ou consultores, mas de forma coletiva, pois deve estar em consonância com o contexto interno em que a organização está inserida (PINTO et al., 2016).

Considerando a premissa de que pessoas são partes essenciais e que conduzem as ações corporativas, entre as quais está o planejamento estratégico, esta pesquisa tem por objetivo investigar a participação na construção do planejamento estratégico como fator de satisfação e influência no clima organizacional.

É válido considerar que o clima organizacional não é algo constante quanto à sua favorabilidade, pois ele sofre influência de uma gama de fatores relacionados ao am- biente de trabalho, desde aspectos psicológicos até sua estrutura física. Assim, o equilíbrio entre as diversas variáveis que compõem o ambiente corporativo, é que vai definir a atmosfera que existirá no cenário da organização.

Os conceitos apresentados nesta pesquisa ajudarão na compreensão das temáticas planejamento estratégico participativo e clima organizacional, que fazem parte do cotidiano das Instituições. Este entendimento oferece um suporte tanto para os gestores, auxiliando na tomada de decisão e condução das atividades, quanto para os demais colaboradores que atuam nos diversos níveis organizacionais, possibilitando diagnosticar problemas, bem como as ferramentas para solucioná-los.

Outra contribuição deste estudo é mostrar que um instrumento sistemático, como o planejamento estratégico, pode ser construído de forma participativa, proporcionando satisfação e fortalecimento da equipe. Desse modo, desenvolver estudos que busquem envolver a equipe com a missão, visão, objetivos e valores da organização, contribuem para uma sólida investigação da relação planejamento estratégico participativo e melhoria do clima organizacional.

\section{REFERENCIAL TEÓRICO}

\subsection{A Participação no contexto da Adminis- tração}

A mudança é uma das características mais significativas das organizações. As transformações são profundas e ocorrem em ritmo cada vez mais dinâmico e acelerado. Nesse contexto, faz-se necessário promover um estilo de administração dinâmico, democrático e que valorize as pessoas 
que fazem parte da organização. A gestão participativa é um processo que objetiva o desenvolvimento da empresa, sem deixar de lado a participação do indivíduo.

Este ambiente altamente mutável exige profissionais mais flexíveis, criativos e com iniciativa para inovar, revelando a necessidade de uma participação mais intensa do funcionário nas atividades da organização. Motta (2001), destaca alguns fatores que justificam o maior envolvimento dos trabalhadores nas gestões das empresas como a democratização das relações sociais, a elevação do nível educacional, a complexidade das empresas modernas, os avanços das ciências, das tecnologias e do conhecimento.

De acordo com Motta (2004), a participação no sentido amplo e teórico do termo, compreende todas as formas e meios pelos quais os membros de uma organização, como indivíduos ou coletividade, podem influenciar os destinos dessa organização. No sentido restrito, pode-se definir a participação como a influência, por parte das pessoas que se encontram abaixo do nível de direção superior, de decisões ou funções usualmente consideradas privativas da gerência ou dos proprietários da empresa.

Acompanhando essa linha de pensamento, Ferreira, Reis e Pereira (2006), afirmam que a participação consiste basicamente na criação de oportunidades para as pessoas influenciem decisões que as afetarão. Essa influência pode variar pouco ou muito. Participação é um caso especial de delegação, na qual o subordinado obtém maior controle, maior liberdade de escolha em relação as suas próprias responsabilidades.

Na mesma linha de raciocínio, Chiavenato (2005), afirma que Administração Participativa é o uso de tomada de decisão con- junta. Através dela, o colaborador participa de uma expressiva condição de poder na tomada de decisão com seus superiores imediatos. Este autor acrescenta que a administração participativa se refere à combinação de recursos organizacionais - humanos, matérias, financeiros, informação e tecnologia - para alcançar objetivos e atingir desempenho excepcional.

Outros autores utilizam o termo "Gestão Participativa" para expressar essa ideia de maior envolvimento do colaborador nas decisões da organização. Na visão de Furtado e Carvalho Neto (2007), por exemplo, a gestão participativa é uma estratégia gerencial utilizada pelas empresas para aumentar sua eficiência e eficácia.

A Gestão Participativa, para Robbins (2009), cria um elo entre os colaboradores e a empresa, pois, a medida que eles passam a conhecer a missão, a visão e os objetivos organizacionais e se identificam com eles, os mesmos passam a contribuir de forma mais pró ativa para que esses objetivos organizacionais sejam alcançados.

Leal Filho (2007) afirma que a participação mobiliza a inteligência da organização, valoriza o potencial das pessoas e permite que elas exprimam suas ideias e emoções e desenvolvam relações pessoais e organizacionais. Para Luck (2008), trabalhar em um clima participativo provoca a melhoria do comportamento, reduz resistência às mudanças e aumenta a produtividade das organizações.

Observa-se do posicionamento dos autores mencionados que a Gestão Participativa proporciona resultados significativos para a organização, principalmente quando há o envolvimento dos colaboradores no processo de tomada de decisão, onde subentende-se que os pontos de vista de todos são 
considerados. Desse modo, a equipe estará mais comprometida com a empresa, contribuindo para o alcance dos objetivos organizacionais.

\subsection{Planejamento Estratégico}

Em um contexto em que ameaças e oportunidades exigem das organizações mudanças adaptativas às transformações ambientais, Kaplan e Norton (2000) ressaltam que as estratégias devem refletir essas transformações. E para que as estratégias logrem êxito faz-se necessário um planejamento.

O planejamento estratégico, como modelo de construção e consolidação das estratégias organizacionais, consiste num processo contínuo baseado em etapas onde são consideradas as variáveis de ambiente da organização, as diretrizes organizacionais e a formulação, a implementação e o controle da estratégia (CERTO; PETER, 2010).

Segundo Hitt, Ireland e Hoskisson (2011), o planejamento estratégico compreende a combinação de compromissos, decisões e ações que irão nortear a organização na obtenção de vantagem competitiva. Nesse processo, acrescentam os autores, devem ser considerados a análise de fatores internos e externos à organização de modo que possibilite a definição da visão e missão organizacional.

Oliveira (2007), acrescenta que o processo decisório deve ocorrer antes, durante e após a elaboração e implementação do planejamento estratégico na empresa. Ressalta que os processos decisórios devem levar em conta aspectos individuais e organizacionais fazendo com que os dois fatores possam confluir seus interesses em prol da estratégia organizacional.
De modo geral, na visão de Kaplan e Norton (2000) as organizações estão cada vez mais percebendo a importância de investir em conhecimento, capacidades e relacionamentos estabelecidos por seus colaboradores. Para os autores, trata-se de investir em recursos intangíveis como forma de estabelecer bases para vantagem competitiva por meio de um planejamento estratégico organizacional, de modo que a consecução da estratégia exige, sobretudo, o alinhamento entre as variáveis de elementos intangíveis da organização.

Mintzberg, Ahlstrand e Lampel (2014) defendem um modelo de gestão estratégica baseada na aprendizagem estratégica organizacional onde a estratégia é formada dinamicamente por qualquer pessoa na organização. Assim, estes autores compreendem que a aprendizagem estratégica, cujo processo de criação acontece de forma coletiva na organização, ajuda a criar e fortalecer a gestão e a cultura estratégica da organização.

Os estudos de Silveira Junior (1995), concluíram que a construção do planejamento estratégico participativo, envolvendo todos os indivíduos dos diversos níveis da organização, torna-se um processo de mudança organizacional. Neste sentido, este processo deve ser caracterizado por um canal aberto de comunicação entre todos da organização, pois, embora a estratégia seja de responsabilidade do nível institucional, o melhor planejador é o indivíduo que está no dia a dia da organização, que conhece as áreas de atuação e coloca em prática as estratégias para o alcance das metas traçadas (CHIAVENATO, 2016). 


\subsection{Clima Organizacional}

Dentre os diversos conceitos relacionados acerca desta temática, Pimenta (2012) afirma que clima organizacional é o reflexo da atmosfera que paira no ambiente de trabalho e sofre influência direta de uma gama de fatores. Nesse sentido, o clima refere-se ao ambiente psicológico interno da instituição que "está intimamente relacionado com o grau de motivação de seus participantes" (CHIAVENATO, 2016, p. 320).

Sanches (2015) é contundente ao afirmar que o clima organizacional é a percepção extraída do coletivo, que se resume na forma como os colaboradores veem a organização. Nesta ótica, eles realizam determinadas avaliações que, consideradas satisfatórias ou não, além de influenciar no comportamento organizacional, podem gerar resultados negativos. Andrade, Fisher e Stefano (2015), reforçam a preocupação das organizações com essa percepção das pessoas em relação ao contexto organizacional.

Assim, Martins (2008) acrescenta que devido ao ambiente mutável e instável em que as organizações estão inseridas, elas têm buscado cada vez mais conhecer sobre a dinâmica organizacional e, além disso, verificar como colaboradores expostos a uma série de estímulos advindos da organização e do ambiente de trabalho, têm percepções similares e acabam gerando significados semelhantes aos aspectos importantes da vida organizacional.

Estes conceitos são importantes para a "compreensão do modo como o contexto do trabalho afeta o comportamento e as atitudes das pessoas neste ambiente, sua qualidade de vida e o desempenho da organização" (MARTINS, 2008, p. 31).

Outro fator relevante, é o papel do ges- tor, que segundo Chiavenato (2016), está relacionado com a motivação de pessoas e equipes. $\mathrm{O}$ autor vai mais a fundo e afirma que a partir do momento em que o gestor proporciona senso de satisfação e autorrealização, contribui efetivamente para se cultivar um clima organizacional leve, incentivador e favorável à produtividade da organização.

No entanto, é importante salientar que, apesar de muitos autores considerarem termos sinônimos, o entendimento proposto por Steuer (1989, apud MARTINEZ E PARAGUAY, 2003, p. 60), prevê que motivação e satisfação possuem conotações diferentes, onde "motivação manifesta a tensão gerada por uma necessidade e satisfação expressa a sensação de atendimento da necessidade". Nesse sentido, Chiavenato (2014) complementa que a satisfação está relacionada à maneira como o colaborador se sente no ambiente organizacional. Desta maneira, a avaliação de satisfação ou não se dá a medida em que as necessidades das pessoas são atendidas pela organização, em suas particularidades.

Já a motivação, segundo Villardi (2011), é um meio pelo qual uma plêiade de razões ou motivos demonstra, induz, incentiva, estimula ou provoca algum tipo de ação ou comportamento humano. Está relacionada "com a personalidade do ser humano e com o seu desenvolvimento mental, emocional, profissional e social" (CUNHA, 2014, p. 61). Ainda segundo o autor, a motivação pode ser considerada uma ação que leva o colaborador a perseguir o alcance e, até mesmo, a superação de determinados objetivos, sendo estes individuais ou organizacionais.

A presente pesquisa elabora um estudo de clima no órgão de gestão de pessoas de 
uma instituição federal de ensino superior, com aspectos altamente peculiares. Segundo Rizzatti (2002), nas universidades, as políticas relacionadas com a gestão de pessoas devem ser baseadas no crescimento profissional dos colaboradores por meio do incentivo a capacitação continuada.

Na visão de Schein (1982), o clima organizacional transforma o comportamento dos colaboradores, por meio de procedimentos administrativos, participação nas decisões políticas e administrativas, reconhecimento e incentivos, influenciando significativamente nos fatores motivacionais dos servidores da Instituição. De acordo com Chiavenato (2016) esta influência do clima também se reflete na maneira como as pessoas percebem a instituição, no relacionamento com colegas e líderes, e como avaliam a estrutura organizacional, o estilo de liderança, a cultura corporativa, os valores e a missão da instituição.

\section{METODOLOGIA}

A pesquisa é uma construção de conhecimento original, conforme determinadas exigências científicas, e para isso são necessários que critérios como: coerência, consistência, originalidade e objetivação sejam obedecidos. Para atender esses critérios é preciso que na metodologia sejam descritos o tipo de pesquisa, o universo e a amostra, o método e o instrumento de coleta de dados, bem como os métodos estatísticos para análise dos resultados (SILVA; MENEZES, 2005). Segundo Collis e Hussey (2005), o capítulo referente a metodologia é o lugar para se explicar os dados coletados.

Do ponto de vista da abordagem do problema, esta pesquisa se caracteriza como qualitativa e quantitativa. Segundo Diehl
(2004), a pesquisa quantitativa faz uso da quantificação, utilizando técnicas estatísticas, objetivando resultados que evitem possíveis distorções de análise e interpretação, possibilitando uma maior margem de segurança.

Já a pesquisa qualitativa, na visão deste mesmo autor, busca compreender e classificar os processos dinâmicos vividos nos grupos, possibilitando o entendimento das mais variadas particularidades dos indivíduos. Marconi e Lakatos (2008), acrescentam que esse tipo de pesquisa apresenta uma preocupação em analisar e interpretar aspectos mais profundos, descrevendo a complexidade do comportamento humano.

Gil (2008) classifica a pesquisa do ponto de vista da natureza, que pode ser básica ou aplicada. A abordagem ao problema pode ocorrer de forma qualitativa ou quantitativa e os objetivos podem ser alcançados através da pesquisa exploratória, descritiva ou explicativa.

Do ponto de vista dos seus objetivos, esta pesquisa é exploratória e descritiva. Coda, (2014), afirma que a pesquisa exploratória visa proporcionar maior conhecimento do assunto, no intento de tornar a pesquisa mais concisa ou elaborar hipóteses. Tratase também de um estudo descritivo porque procura descrever as características de uma experiência. De acordo com Gil (2008), uma das peculiaridades desse tipo de pesquisa está na utilização de técnicas padronizadas de coleta de dados, tais como o questionário e a observação sistemática.

O universo amostral deste estudo foi a Pró-Reitoria de Gestão de Pessoas - PROGEP, da Universidade Federal do Amapá UNIFAP. Fazem parte desta Pró-Reitoria 41 servidores efetivos pertencentes ao quadro técnico administrativo. De acordo com as 
listas de frequência, 32 pessoas participaram da construção do planejamento estratégico da PROGEP. Obteve-se um total de 22 servidores que responderam ao questionário, no período de 01 a 08 de agosto de 2016, correspondendo a uma parcela de $69 \%$ do público-alvo da pesquisa, sendo portanto, uma amostra significativa.

Para investigar a participação na construção do Planejamento Estratégico como fator de satisfação e influência no Clima Organizacional, esta pesquisa foi desenvolvida nas seguintes etapas: a) Definição da problemática e objetivo; b) Definição das variáveis organizacionais; c) Montagem do instrumento; d) Definição de parâmetros; e) Aplicação e coleta da pesquisa; f) Tabulação dos dados; e g) análise e interpretação dos resultados com a estatística descritiva para a dimensão quantitativa do artigo.

Foram escolhidas as variáveis Gestão Participativa, Planejamento Estratégico e Clima Organizacional para verificar a satisfação dos servidores em relação a alguns aspectos da PROGEP. À cada variável foi atribuída uma pequena série de perguntas. A escolha dessas variáveis advem da filtragem de resultados de estudos sobre o processo de construção do planejamento estratégico e seus efeitos sobre a organização.

A escolha da variável Gestão Participativa teve como base o estudo de Forte (2003), que propõe um modelo de plano estratégico elaborado de forma participativa para garantir ações que incorporem grandes resultados. Quanto a variável Planejamento Estratégico, Barbosa e Brondani (2004) mostram a importância de ser utilizado como ferramenta fundamental para direcionar e auxiliar o correto gerenciamento das organizações. A escolha da variável Clima Organizacional é baseada no trabalho de
Santos (2000), que aponta um método para desenvolver o diagnóstico do clima organizacional, baseado na influência de certos fatores, para melhoria contínua da relação indivíduo-organização.

Um dos instrumentos de pesquisa utilizados foi a entrevista semi-estruturada com as três principais gestoras da PROGEP (Pró-Reitora e Diretoras), no intuito de verificar suas percepções sobre a participação da equipe na construção do planejamento estratégico e se esta participação influenciou no clima organizacional. Segundo Boni (2005), a entrevista semi-estruturada é composta por questões abertas e fechadas, na quais os respondentes têm a possibilidade de fazer as considerações necessárias sobre o sobre o tema proposto.

Outro instrumento de pesquisa usado foi o questionário, aplicado eletronicamente com a autorização da Pró-Reitoria, composto por 25 questões, sendo 24 questões fechadas e 1 aberta, configuradas com afirmativas e interrogativas. Estas questões ofereceram respostas em forma de escala do tipo Likert, com variação de 1 a 5 pontos, onde 1 significa que o servidor discorda totalmente e 5 demonstra que ele concorda totalmente, por exemplo. Segundo Potrich (2012), esse tipo de escala processa o nível de concordância ou discordância dos colaboradores em relação às questões submetidas.

Luz (2003), acrescenta que nesse método de escala Likert o respondente poderá manifestar-se com maior precisão e na tabulação dos dados será possível graduar o grau de intensidade de satisfação ou insatisfação dos participantes em relação à questão.

Foram formulados parâmetros para facilitar a tabulação dos dados, visando a meIhor adequação das diferentes opções de 
respostas ao objetivo da pesquisa. Luz (2003), ressalta que cada opção de resposta deve ser interpretada na tabulação, como manifestação de satisfação ou insatisfação do respondente.

Pelos parâmetros definidos, ao se tabular uma pergunta, serão considerados "satisfeitos" os servidores que optarem pelas respostas "Mais concordo que discordo" e "Concordo totalmente". As respostas "Mais discordo que concordo" e "Discordo totalmente", serão consideradas como manifestação de insatisfação. Na opção "Nem concordo nem discordo", tabula-se só o percentual.

Definida a parametrização, passou-se à aplicação e coleta de dados, que ocorreu através da submissão do questionário aos servidores da PROGEP, por meio da ferramenta Google Drive. As questões foram enviadas para o e-mail dos respondentes. A identificação dos entrevistados foi mantida em sigilo, conforme recomenda Cunha (2014), para não interferir no resultado da pesquisa, bem como para garantir o máximo de sinceridade, no sentido de obter dados mais fiéis.

Posteriormente, passou-se à tabulação dos dados para verificar os percentuais de satisfação dos servidores em relação as três variáveis escolhidas. Incialmente a tabulação foi realizada para verificar o grau de satisfação dos participantes em relação a cada pergunta.

Logo após, utilizando a estatística descritiva, tabulou-se por variável, sendo consideradas todas as perguntas inseridas na variável, possibilitando obter o nível de satisfação para cada assunto abordado. O percentual de satisfação de cada variável corresponde à média aritmética dos percentuais de satisfação das perguntas que compõem a variável. Em seguida, de forma análoga, foi realizada a tabulação geral, considerando as três variáveis abordadas.

Por fim, foi realizada análise estatística através da técnica correlações de Pearson, gerada por meio do programa estatístico IBM SPSS Statistics Base 22.0, para avaliar a correlação entre sete variáveis que afetam o clima organizacional.

\section{ANÁLISE E DISCUSSÃO DOS RESULTADOS}

Serão apresentados os resultados das análises quantitativa e qualitativa dos questionários e das entrevistas aplicados aos servidores e gestores da PROGEP, respectivamente. A priori será mostrada a análise por variável e posteriormente se fará a análise geral dos resultados da pesquisa.

Os servidores possuíam em sua maioria (46\%) idade entre 18 e 30 anos, sendo que os demais se dividiam em: $36 \%$ entre 31 e 40 anos; $14 \%$ acima de 51 anos e $5 \%$ entre 41 e 50 anos. $64 \%$ são pessoas do sexo feminino. Quanto ao nível de instrução, 55\% da amostra, possui Especialização; $23 \%$ possuem Ensino Médio/Técnico; 19\% têm Graduação e 5\%, Mestrado. 55\% desses 22 servidores estão na Instituição de 1 a 3 anos; $23 \%$ há menos de 1 ano e $23 \%$ fazem parte do quadro institucional há mais de 3 anos.

\subsection{Gestão participativa}

O gráfico 1, mostra o grau de satisfação da variável "Gestão Participativa" (82\%), e os percentuais de satisfação para cada pergunta desta série. Esta variável abordou os seguintes aspectos: a) fomento da gestão participativa (pergunta 6); b) feedback, incentivo e reconhecimento por parte do líder na construção do planejamento estra- 
tégico (perguntas 7, 8 e 11, respectivamente); c) oportunidade e liberdade para ideias e críticas (pergunta 9); d) satisfação proporcionada em construir o planejamento estratégico (pergunta 10) e e) disponibilidade do líder em sanar dúvidas (pergunta 12).

Gráfico 1. Percentuais da variável Gestão Participativa

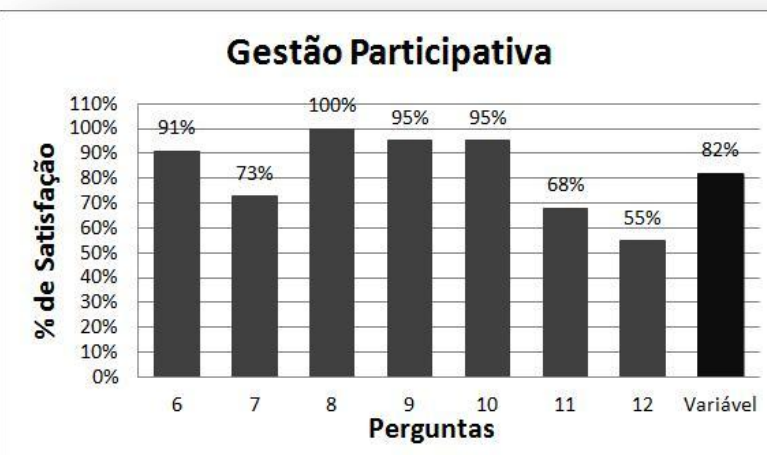

Fonte: Pesquisa dos autores (2016).

O gráfico mostra que os percentuais de satisfação para as perguntas tendem a se aproximar de 100\%. A pergunta 8, "Seu líder incentivou sua participação no planejamento estratégico da PROGEP?”, obteve $100 \%$ de satisfação. As perguntas "Na elaboração do planejamento estratégico, houve oportunidade e liberdade para dar idéias e fazer críticas" e "A participação na elaboração do planejamento estratégico me proporcionou satisfação", obtiveram percentual de $95 \%$ de satisfação pelos respondentes.

Em relação à entrevista com as gestoras, quando perguntado se "Na elaboração do planejamento estratégico, houve oportunidade e liberdade para os colaboradores darem ideias e fazerem críticas", todas as respostas evidenciaram que foi dada a oportunidade aos servidores de opinar, sugerir e até mesmo questionar acerca de determinados pontos do planejamento.

Acerca deste fator, uma das entrevista- das respondeu: "A metodologia utilizada envolveu toda a PROGEP. Nós erámos divididos em grupos e nos grupos nós tínhamos a oportunidade de opinar, de sugerir. As pessoas se envolveram e participaram com afinco. Tiveram a oportunidade de falar sobre as suas atividades".

Outra pergunta da entrevista indagou se "Há na PROGEP uma cultura baseada na gestão participativa? por quê?". As respostas foram afirmativas. Uma das gestoras relatou: " A partir do momento que a gestão reúne, deixa para a equipe a possibilidade de dar sugestões na tomada de decisões e assim a gente tem essa oportunidade de participar e opinar". Outra resposta ressalta: "Nas decisões a serem tomadas, as equipes que compõem esta Pró-Reitoria, participam, dando sugestões e feedback para que o gestor tome determinada decisão."

Desta forma, as respostas das gestoras convergem com os resultados do questionário exibidos no gráfico anterior. Assim, pode-se afirmar que a gestão da Progep busca inserir seus colaboradores em suas politicas e em seus processos decisórios. Consequentemente esses servidores têm a percepção que estão inseridos nesse contexto de Gestão Participativa, pois Ihes são oferecidas oportunidades para o diálogo e a participação.

\subsection{Planejamento estratégico}

O gráfico 2, mostra os resultados da variável "Planejamento Estratégico", em que verificou-se um percentual de $90 \%$ de satisfação dos servidores. $86 \%$ dos participantes se consideram responsáveis pelo alcance dos objetivos traçados no Planejamento estratégico (pergunta 13) e $82 \%$ afirmaram 
que estão empenhados para alcançar esses objetivos (pergunta 16).

Gráfico 2. Percentuais da variável Planejamento Estratégico

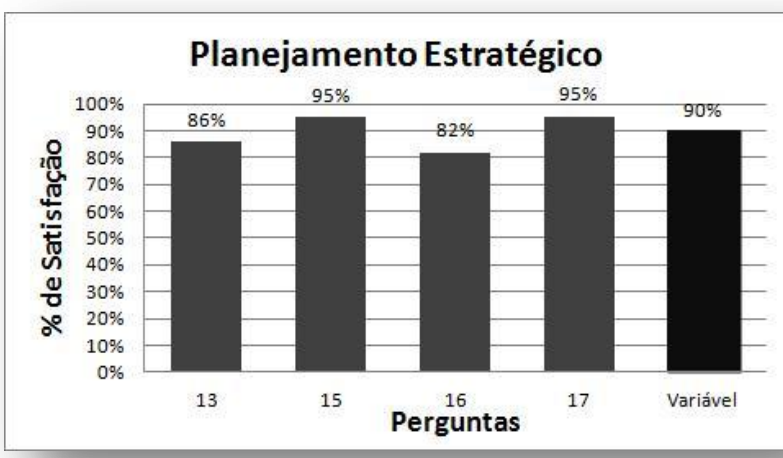

Fonte: Pesquisa dos autores (2016).

Um ponto a se destacar no gráfico acima se refere às perguntas 15 e 17, que alcançaram um nível significativo de satisfação dos servidores (95\%). Os respondentes foram categóricos ao considerarem que no processo de construção do Planejamento estratégico houve envolvimento e interação entre as equipes (pergunta 15), bem como, busca pelo consenso nas discussões (pergunta 17).

$\mathrm{Na}$ entrevista com as gestoras, um dos aspectos abordados foi quanto as contribuições que a construção coletiva do Planejamento Estratégico trouxe ao ambiente organizacional da PROGEP. As respostas apontam que essa participação possibilitou aos servidores visualizarem a sua importância para a Instituiçao, bem como, adquirir a convicção de que as atividades que executam são fundamentais para o desenvolvimento da Organização.

Nesse sentido, uma das gestoras afirmou que uma das conquistas dessa participação coletiva na construção do planejamento da PROGEP, "foi perceber que cada pessoa, cada tarefa, cada ação que é desenvolvida, faz parte de um plano maior. Isso valoriza o trabalho das pessoas, faz com que você se sinta importante para a instituição, pois você vê que a instituição depende de você e das atividades que você executa."

Esses resultados remetem à ideia de que a construção coletiva do planejamento da PROGEP trouxe resultados significativos para a equipe, pois a metodologia utilizada abriu espaço para a discussão e interação entre os participantes. Este ambiente de integração culminou na percepção pelos servidores de que o trabalho que desempenham é essencial para alcançar os objetivos institucionais. Desta maneira, todos se sentiram motivados e comprometidos em alcançar as metas traçadas.

\subsection{Clima organizacional}

Quanto a variável "Clima Organizacional", foi solicitado aos participantes que avaliassem sua satisfação em relação a fatores que integram o ambiente organizacional da PROGEP. Os fatores com maior grau de satisfação (entre $70 \%$ e $80 \%$ ) foram: ambiente psicológico, liderança, equipe, reconhecimento e respeito. Já os fatores de estrutura física e equipamentos alcançaram percentuais críticos de satisfação, 23\% e $32 \%$, respectivamente.

Resultado similar houve nas respostas das entrevistas, em que foi perguntado "Quais fatores do ambiente organizacional da PROGEP, você considera pontos fortes e pontos fracos para a satisfação da sua equipe?". Obteve-se a seguinte resposta de uma das gestoras: "Considero um ponto forte o fato de haver uma preocupação da gestão no sentido de promover e participar de atividades que busquem a interação pessoal e o envolvimento dos servidores. Em contra- 
partida, a estrutura física não é apropriada para comportar a equipe."

No gráfico 3, observa-se um grau elevado de satisfação dos servidores (85\%), para o Clima Organizacional. Os participantes afirmaram que fazer parte da construção do planejamento incentivou o trabalho em equipe (pergunta 18) e influenciou nos processos de tomada de decisão (pergunta 19), onde se nota $95 \%$ e $78 \%$ de satisfação, respectivamente. Nas perguntas: como os servidores avaliaram o relacionamento com o líder (pergunta 20) e com os colegas de trabalho (pergunta 21), após o processo de elaboração do planejamento, houve um percentual de satisfação de $86 \%$ e $95 \%$, respectivamente.

Gráfico 3. Percentuais da variável Clima Organizacional.

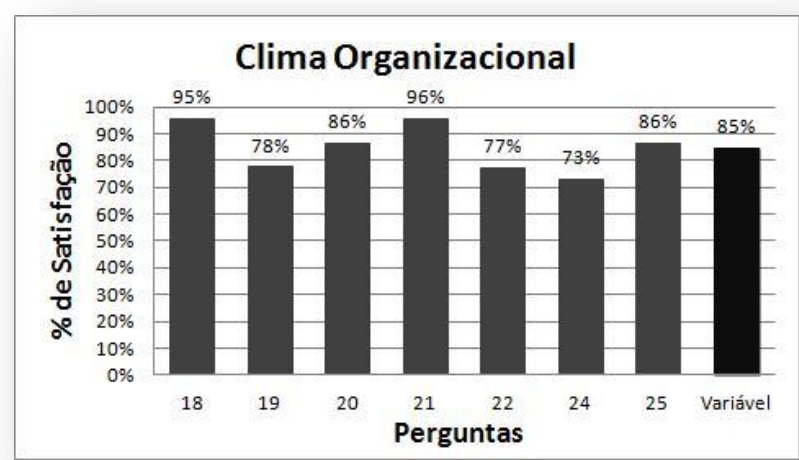

Fonte: Pesquisa dos autores (2016).

Na pergunta 22, do gráfico acima, os respondentes afirmaram que existe na PROGEP uma cultura baseada na gestão participativa (77\%). A pergunta 24 mostra que $73 \%$ dos participantes consideram que a PROGEP é aberta a receber sugestões e contribuições de seus colaboradores. A pergunta 25 , aponta que $86 \%$ dos servidores indicariam a PROGEP para um amigo trabaIhar.

As análises abordadas pelo gráfico, apon- tam para um clima organizacional favorável no ambiente da PROGEP. Corroborando esta afirmação, a entrevista com as gestoras evidencia fatores positivos na motivação dos servidores. Quando perguntado acerca dos fatores que mais motivam os colaboradores da PROGEP, uma das entrevistadas citou a autonomia e descentralização na execução de atividades, o reconhecimento pelo trabalho desenvolvido, a definição de metas e o respeito às ideias e problemas colocados pela equipe.

Outra resposta a ser destacada na entrevista, quanto aos fatores motivacionais dos servidores, é a importância de se ter no ambiente de trabalho um relacionamento interpessoal favorável com os colegas e com a chefia. Afirma uma das gestoras: "Precisamos nos sentir aceitos, cuidados e receber estima das pessoas (...) eu vejo isso muito forte na progep. Há uma interação, um relacionamento interpessoal muito agradável entre os servidores".

Nesse contexto em que as gestoras identificaram os elementos que motivam os colaboradores da PROGEP, observa-se que tais elementos foram oportunizados e concretizados através da forma participativa de construção de um instrumento de planejamento para a Pró-Reitoria de Gestão de Pessoas, como já visto na análise dos questionários, das variáveis "Gestão Participativa" e "Planejamento Estratégico". Este fato portanto, confirma a relação planejamento estratégico participativo com clima organizacional positivo no ambiente de trabalho.

\subsection{Análise geral dos resultados da pesqui- sa}

Além de calcular os percentuais de satisfação dos participantes quanto às três vari- 
áveis abordadas na pesquisa, Luz (2003) afirma que faz-se necessário calcular o grau de satisfação dos participantes em relação à pesquisa como um todo, ou seja com relação ao conjunto das variáveis pesquisadas. Assim, este percentual calculado representa - resultado geral da pesquisa, também chamado de ISG - Índice de Satisfação Geral.

Este Índice de Satisfação Geral, é obtido através da média aritmética dos percentuais de satisfação dos participantes, considerando todas as variáveis pesquisadas. O gráfico 4 mostra o ISG em relação às variáveis gestão participativa, planejamento estratégico e clima organizacional. Observa-se que as três variáveis apresentaram níveis elevados de satisfação $(82 \%, 90 \%$ e $85 \%$, respectivamente) e portanto o resultado geral da pesquisa indica um grau de $86 \%$ de satisfação.

Figura 4. Gráfico do ISG - Índice de Satisfação Geral

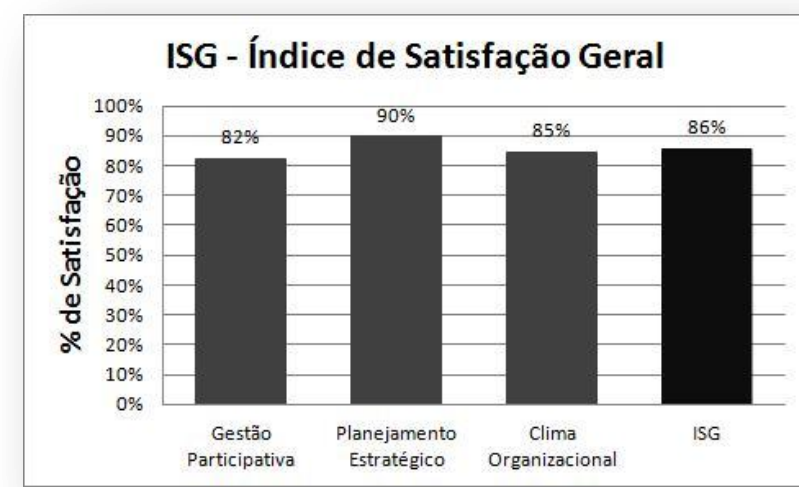

Fonte: Pesquisa dos autores (2016).

Outro ponto a ser destacado nesta pesquisa, é a análise estatística das correlações de Pearson, com base nos conceitos de Dancey e Reidy (2005), que apontam a seguinte classificação: $r=0,10$ até 0,30 (fraco); $r=0,40$ até 0,6 (moderado); $r=0,70$ até 1 (forte). Assim, a correlação de nível
0,01 é considerada significativa, enquanto que a correlação de nível 0,05 é considerada altamente significativa. A tabela 1 expõe a relação de significância entre alguns fatores do ambiente organizacional da PROGEP.

Tabela 1. Coeficientes de correlação de Pearson entre sete variáveis que influenciam no clima organizacional da PROGEP.

\begin{tabular}{|c|c|c|c|c|c|c|c|}
\hline $\begin{array}{l}\text { Corre- } \\
\text { lação }\end{array}$ & $\begin{array}{l}\text { Ambi- } \\
\text { ente } \\
\text { Psico- } \\
\text { lógico }\end{array}$ & $\begin{array}{c}\text { Estru- } \\
\text { tura } \\
\text { Física }\end{array}$ & $\begin{array}{l}\text { Lide- } \\
\text { rança }\end{array}$ & $\begin{array}{l}\text { Equi- } \\
\text { pam. }\end{array}$ & $\begin{array}{l}\text { Equi- } \\
\text { pe }\end{array}$ & $\begin{array}{l}\text { Res- } \\
\text { peito }\end{array}$ & $\begin{array}{c}\text { Carga } \\
\text { de } \\
\text { Traba- } \\
\text { Iho }\end{array}$ \\
\hline $\begin{array}{l}\text { Ambi- } \\
\text { ente } \\
\text { Psico- } \\
\text { lógico }\end{array}$ & 1 & ,358 & ,685 & 174 & ,344 & $753^{* *}$ &, $530^{*}$ \\
\hline $\begin{array}{l}\text { E. } \\
\text { Física }\end{array}$ & 358 & 1 & ,314 &, $424^{*}$ & -,059 & 209 & 396 \\
\hline $\begin{array}{l}\text { Lide- } \\
\text { rança }\end{array}$ & $685^{* *}$ & ,314 & 1 & 202 & ,098 &, $531^{*}$ & ,735 \\
\hline $\begin{array}{l}\text { Equipa } \\
\text { pa- } \\
\text { mento }\end{array}$ & 174 & ,424 & ,202 & 1 & -375 &,- 124 & ,209 \\
\hline Equipe & ,344 &,- 059 & ,098 & -375 & 1 & ,641 &,- 029 \\
\hline $\begin{array}{l}\text { Res- } \\
\text { peito }\end{array}$ &, $753^{* *}$ & 209 &, $531^{*}$ & -124 & 641 & 1 & ,345 \\
\hline $\begin{array}{l}\text { C. } \\
\text { Traba- } \\
\text { Iho } \\
\end{array}$ &, $530^{*}$ & ,396 &, $735^{* *}$ & 209 &,- 029 & 345 & 1 \\
\hline$N$ & 22 & 22 & 22 & 22 & 22 & 22 & 22 \\
\hline
\end{tabular}

Nessa lógica, é possível verificar que ambiente psicológico sofre influência significativa de valor moderado de liderança $\left(685^{* *}\right)$, significativa forte de respeito $\left(753^{* *}\right)$ e altamente significativa de carga de trabalho $\left(530^{*}\right)$. Assim é possível inferir que, na percepção dos colaboradores da PROGEP, para se ter um ambiente psicológico saudável, é necessário que haja um bom relacionamento com a liderança, alto nível de respeito e uma carga de trabalho proporcional às atribuições e capacidades dos colaboradores.

É possível sintetizar ainda que os colaboradores consideram que o respeito entre os indivíduos da organização é significativo para se ter uma equipe sólida $\left(r=641^{* *}\right)$, 
bem como altamente significativo para se ter uma boa liderança $\left(531^{*}\right)$.

Todas estas variáveis obtiveram avaliações positivas por parte da equipe, durante a participação no planejamento estratégico, o que influenciou favoravelmente no clima organizacional. Assim, aspectos relevantes foram ressaltados como: gestão participativa, interatividade, comprometimento, aprendizado e envolvimento entre as equipes. O consenso entre os colaboradores sobre o incentivo fornecido pela liderança, para participação de toda a equipe no planejamento estratégico, correlaciona-se significativamente com a liberdade de propor sugestões e fazer críticas, bem como fomenta a prática da gestão participativa.

Considerando que o conceito de clima organizacional engloba o nível de satisfação dos funcionários de uma organização, acerca de vários fatores e que influencia a motivação e o comportamento dessas pessoas, pode-se notar que as respostas dos questionários mostraram relevantes índices percentuais (acima de $80 \%$ ) de satisfação para as três variáveis abordadas, bem como evidenciaram a motivação dos servidores da PROGEP, refletindo desta forma na melhoria do ambiente de trabalho.

Outro ponto a destacar é que estas variáveis foram compostas por perguntas que abarcam as dimensões de clima organizacional. Assim, observou-se nos resultados que a participação dos servidores na construção do planejamento estratégico da PROGEP proporcionou um clima organizacional favorável e positivo entre os mesmos. A análise das entrevistas com as gestoras corrobora também esta afirmação. Deste modo, os resultados expostos evidenciam uma relação entre processo participativo na construção do planejamento estratégico e percepção coletiva satisfatória quanto ao ambiente organizacional.

Os resultados expostos indicam que quando a gestão da PROGEP deu prioridade e incentivo para a equipe compor a construção do planejamento estratégico, os servidores sentiram-se motivados e valorizados pelo trabalho que desempenhavam. Isto possibilitou o empoderamento da equipe que se envolveu com a missão, as metas e os valores da instituição, o que refletiu na integração, colaboração e no relacionamento entre gestores e colegas de trabalho, bem como, no grau de satisfação dos servidores em fazer parte da construção de um instrumento importante para o alcance dos objetivos institucionais.

\section{CONCLUSÃO}

Considerando o que foi exposto, pode-se afirmar que o objetivo da pesquisa de investigar a participação na construção do Planejamento Estratégico como fator de satisfação e influência no Clima Organizacional, foi alcançado, evidenciando que envolver as pessoas nas decisões e na elaboração de instrumentos estratégicos da organização, contribui para fomentar a gestão participativa e melhorar os relacionamentos entre os envolvidos.

Nesse sentido, verificou-se que houve empenho da equipe da PROGEP no processo de construção de seu Planejamento Estratégico, bem como, um gerenciamento baseado no empoderamento, onde os colaboradores se sentiram totalmente responsáveis pelo alcance dos objetivos do planejamento. Esse envolvimento se mostrou um indicador contributivo para um bom ambiente de trabalho, refletindo portanto no clima organizacional. 
A gestão participativa remete a uma ação transparente, baseada no diálogo e com possibilidades de resultados positivos, considerando que a construção coletiva é o somatório do comprometimento de colaboradores e gestores que visam melhorar os resultados da organização. E nesse sentido, a gestão da PROGEP incentivou a participação, fornerceu feedback e reconhecimento aos servidores na construção do planejamento estratégico, proporcionando oportunidade para novas ideias, críticas e compartilhamento de experiências.

Desta forma, a dinâmica e a metodologia participativa aplicada na construção do planejamento estratégico, refletiu diretamente no clima organizacional da PROGEP, pois influenciou no processo de tomada de decisão, incentivou o trabalho em equipe e aprimorou a integração entre os colaboradores e destes com os gestores. Isto possibilitou uma melhor percepção dos servidores em relação ao ambiente organizacional, que passaram a ter a visão de uma cultura baseada na gestão participativa e aberta a receber contribuições.

Esta pesquisa apresenta temáticas relevantes e fornece subsidios para aquisição de informação e aprendizagem, pois aborda assuntos que fazem parte do cotidiano das organizações como Gestão Participativa, Planejamento Estratégico e Clima Organizacional e que muitas vezes apresentam pontos críticos que impedem o alcance dos objetivos organizacionais. Compreender a dinâmica desses processos e suas relações no ambiente de trabalho facilitará o diagnostico de situações e a tomada de decisão, no sentido de aprimorar métodos mais eficazes para o desenvolvimento da organização e das pessoas que a compõe.

Deste modo, trazer à discussão as temá- ticas abordadas neste trabalho, contribui para subsidiar as organizações a desenvolver um clima organizacional positivo, favorecendo a produtividade, a criatividade, a motivação e os resultados alcançados. Estes fatores são fundamentais para as instituições, considerando o contexto dinâmico e altamente mutável que as cercam, onde se faz necessário gerenciar de forma eficiente os recursos e as pessoas que compõem o ambiente corporativo para que se possa atingir os objetivos traçados.

Diante do exposto, espera-se que os resultados da pesquisa estimulem novas investigações sobre o tema abordado, visto que, o planejamento estratégico participativo constitui-se em um dos diversos instrumentos que pode ser utilizado para contribuir com a melhoria do ambiente organizacional. Portanto, este trabalho abre um leque de possibilidades para estudos posteriores, servindo como norteador na busca de se implementar e incentivar ações que proporcionem a participação dos colaboradores nos processos decisórios, bem como, desenvolvam estratégias para a construção de um clima organizacional favorável.

\section{REFERÊNCIAS}

ANDRADE, Sandra Mara de; FISCHER, André Luiz; STEFANO, Silvio Roberto. Confiança organizacional e interpessoal como uma dimensão de clima organizacional. Revista de Administração e Contabilidade da Unisinos, São Leopoldo, v. 12, n. 2, p.155-166, jun. 2015. Trimestral.

BARBOSA, Emerson Rodrigues; BRONDANI, Gilberto. Planejamento estratégico organizacional. Revista Eletrônica de Contabilidade, v. 1, n. 2, p. 123, 2004.

BONI, Valdete. Aprendendo a entrevistar: 
como fazer entrevistas em ciências sociais. Revista Eletrônica dos Pós-graduandos em Sociologia Política da Ufsc, Santa Catarina, v. 2, n. 13, p.60-80, jul. 2005. Semestral. CERTO, S. C.; PETER, J. P.. Administração estratégica: planejamento e implantação da estratégia. 3. ed. São Paulo: Pearson Education do Brasil, 2010.

CHIAVENATO, Idalberto. Administração nos novos tempos. 2. ed. Rio de Janeiro: Elsevier, 2005.

CHIAVENATO, Idalberto. Comportamento organizacional: a dinâmica do sucesso das organizações. 3. ed. São Paulo: Manole, 2014.

CHIAVENATO, Idalberto. Fundamentos de administração: planejamento, organização, direção e controle para incrementar competitividade e sustentabilidade. Rio de Janeiro: Elsevier, 2016.

CODA, R.; CODA, D. A. Desempenho estratégico do departamento de gestão de recursos humanos: uma pesquisa exploratória acerca das implicações dos estilos comportamentais de seus profissionais. Brazilian Business Review, v. 11, n. 4, p. 116-140, 2014.

COLLIS, J.; HUSSEY, R. Pesquisa em administração: um guia prático para alunos de graduação e pós-graduação. 2. ed. Porto Alegre: Bookman, 2005.

CUNHA, Paulo Roberto da et al. Pesquisa de clima organizacional: um estudo realizado em uma indústria de alimentos na cidade de Gaspar, SC. Race - Revista de Administração, Contabilidade e Economia, Santa Catarina, v. 3, n. 1, p.59-78, abr. 2014. Trimestral.

DANCEY, Christine P.; REIDY, John. Estatística sem matemática para psicologia: Usando SPSS para Windows. 3. ed. Porto Alegre: Artmed, 2006.
DIEHL, Astor Antonio. Pesquisa em ciências sociais aplicadas: métodos e técnicas. São Paulo: Prentice Hall, 2004.

FERREIRA, Ademir Antonio; REIS, Ana Carla Fonseca; PEREIRA, Maria Isabel. Gestão empresarial: De Taylor aos novos dias, evolução e tendência da moderna administração. São Paulo: Copyright, 2006.

FILHO, José Garcia Leal. Gestão estratégica participativa: teoria e prática para criação de organizações que aprendem. 2. ed. revisada e atualizada. Curitiba: Juruá, 2007.

FORTE, A. M. S. A construção do planejamento estratégico de turismo de Juiz de Fora, MG. Caderno Virtual de Turismo, v. 3, n. 3, p. 7-13, 2003.

FURTADO, R.; CARVALHO NETO, A. M. Uma contribuição para a construção de um modelo de análise da gestão participativa de empresas. Anais do EnGPR, Natal, RN, 2007.

GIL, Antonio Carlos. Como elaborar projetos de pesquisa. 5. ed. São Paulo: Atlas, 2008.

HITT, M. A.; IRELAND, R. D.; HOSKISSON, R. E. Administração estratégica: competitividade e globalização. 2. ed. São Paulo: Cengage Learning, 2011.

KAPLAN, R. S.; NORTON, D. P. Organização orientada para a estratégia: como as empresas que adotam o balanced scorecard prosperam no novo ambiente de negócios. 17. ed. Rio de Janeiro: Elsevier, 2000.

LUCK, H. A gestão participativa na escola. 3. ed. Petrópolis: Vozes, 2008. (Série Cadernos de Gestão).

LUZ, Ricardo Silveira. Gestão do clima organizacional: propostas de critérios para metodologia de diagnóstico, mensuração e melhoria. Estudo de caso em organizações nacionais e multinacionais localizadas na cidade do Rio de Janeiro. 2003. 182 f. Dis- 
sertação (Mestrado) - Curso de Sistemas de Gestão, Universidade Federal Fluminense, Niterói, 2003.

MARCONI, Marina de Andrade; LAKATOS, Eva Maria. Fundamentos de metodologia científica. 6. ed. São Paulo: Atlas, 2005. 315p. Reimp. 2008.

MARTINEZ, M. C.; PARAGUAY, A. I. B. B. Satisfação e saúde no trabalho: aspectos conceituais e metodológicos. Cadernos de Psicologia Social do Trabalho, v. 6, p. 59-78, 2003.

MARTINS, M. C. F. Clima organizacional. In: M.M.M. SIQUEIRA (org.), Medidas do comportamento organizacional: ferramentas de diagnóstico e gestão. Porto Alegre, Artmed, p. 29-40, 2008.

MINTZBERG, Henry; AHLSTRAND, Bruce; LAMPEL, Joseph. Safári de estratégia: um roteiro pela selva do planejamento estratégico. 2. ed. Porto Alegre: Bookman, 2014.

MOTTA, F. C. P. Teorias das organizações: evolução e crítica. 2. ed. São Paulo: Pioneira Thompson Learning, 2001.

MOTTA. Paulo Roberto. Gestão contemporânea: a ciência e arte de ser dirigente. 15. ed. Rio de Janeiro e São Paulo: Record. 2004.

OLIVEIRA, Djalma de Pinho Rebouças de. Planejamento estratégico: conceitos, metodologias e práticas. 23. ed. São Paulo: Atlas, 2007.

PIMENTA, R. C. Q.; OLIVEIRA, J. A.; AOUAR, W. A. Clima organizacional em instituto de pesquisa tecnológica. RAUnP - Revista Eletrônica do Mestrado Profissional em Administração da Universidade Potiguar, v. 4, n. 2, p. 23-38, 2012.

PINTO, L. B.; BOAS, A. A. V.; ANTONIALLI, L. M.; SILVA, N. R. Gestão de pessoas e planejamento estratégico em hospitais do sul de Minas Gerais: uma análise de indicado- res. Contextus - Revista Contemporânea de Economia e Gestão, v. 14, n. 1, p. 107-134, 2016.

POTRICH, Ani Caroline G. Clima Organizacional: um estudo quantitativo em uma empresa de Santa Maria - RS. in: ENCONTRO NACIONAL DE ENGENHARIA DE PRODUCAO, 32. 2012. Anais... Bento Gonçalves: ABEPRO, 2012.

RIZZATTI, Gerson. Categorias de análise de clima organizacional em universidades federais brasileiras. 2002. 305 f. Tese (Doutorado) - Curso de Engenharia de Produção, Universidade Federal de Santa Catarina, Florianópolis, 2002. Disponível em: <https://repositorio.ufsc.br/handle/123456 789/84206>. Acesso em: 02 ago. 2016.

ROBBINS, Stephen Paul. Fundamentos do comportamento organizacional. Tradução técnica Reynaldo Marcondes. São Paulo: Pearson Prentice Hall, 2009.

SANCHES, João Paulo dos Santos. Relação entre a percepção do clima organizacional e o comportamento organizacional positivo: estudo no setor de obras da prefeitura de tamboara - PR. Revista de Administração, Contabilidade e Sustentabilidade, Campina Grande, v. 5, n. 3, p.19-39, 05 dez. 2015.

SANTOS, N. M. B. F. D. Gestão estratégica nas instituições de P\&D: um enfoque centrado na pesquisa de clima organizacional. Revista Administração em Diálogo, v. 2, n. 1, p. 1-18, 2000.

SCHEIN, Edgar H. Psicologia organizacional. Rio de Janeiro: Prentice-Hall, 1982.

SILVA, E.; MENEZES, E. Metodologia da pesquisa e elaboração de dissertação. Florianópolis: UFSC/PPGEP/LED, 2005.

SILVEIRA JÚNIOR, Aldery. Planejamento estratégico como instrumento de mudança organizacional. 1995. 215 f. Dissertação (Mestrado em Administração) - Universida- 
de de Brasília, Brasília, 1995.

VILLARDI, Beatriz Queiroz. Uma metodolo-

gia para diagnóstico de clima organizacio-

nal: integrando motivos sociais e cultura

brasileira com fatores do ambiente de trabalho do poder judiciário. Revista de Administração Pública, Rio de Janeiro, v. 45, n. 2, p.303-329, abr. 2011. Bimestral.

Artigo recebido em 10 de agosto de 2017.

Aprovado em 29 de novembro de 2017. 